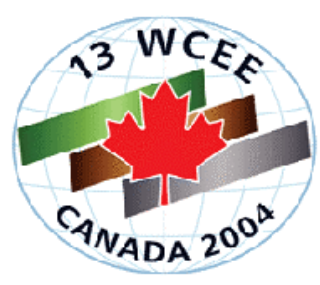

$13^{\text {th }}$ World Conference on Earthquake Engineering
Vancouver, B.C., Canada
August 1-6, 2004
Paper No. 1819

\title{
THE ATC-58 PROJECT: DEVELOPMENT OF NEXT-GENERATION PERFORMANCE-BASED EARTHQUAKE ENGINEERING DESIGN CRITERIA FOR BUILDINGS
}

\author{
Ronald HAMBURGER ${ }^{1}$, Chris ROJAHN ${ }^{2}$, Jack MOEHLE $^{3}$, Robert BACHMAN $^{4}$, \\ Craig COMARTIN ${ }^{5}$, Andrew WHITTAKER ${ }^{6}$
}

\begin{abstract}
SUMMARY
Under sponsorship of the Federal Emergency Management Agency, the Applied Technology Council is engaged in a multi-year effort to develop next-generation performance-based seismic design criteria. The criteria will be applicable to the design of new buildings or the retrofit of existing buildings. Constructed around a structural reliability framework, the criteria will permit the design of buildings to meet specific performance objectives expressed with regard to potential earthquake-related human casualties, repair costs and interruption of building occupancy and facility function. Recognizing the varied capabilities and needs of stakeholders in considering these losses, the criteria will permit expression of performance in either a probabilistic or scenario-based manner. The first phases of the project are focused on development of practical procedures for predicting building performance. This performance assessment procedure includes characterization of site seismicity through ground motion intensity hazard functions, development of structural response functions that relate probable amplitude of structural response as a function of ground motion intensity, damage functions that relate the probability of experiencing different damage states as a function of the response parameters, loss functions that relate the probability of experiencing casualty, economic and occupancy losses as a function of damage and practical procedures to integrate these functions to express building performance in the form of projected losses. The project is being conducted in coordination with parallel efforts the by the three U.S. national centers for earthquake engineering research in order to take advantage of significant research at these centers. In addition the project is coordinating with parallel efforts in the blast and fire protection communities as well as those underway by the model building codes and standards development organizations.
\end{abstract}

\footnotetext{
${ }^{1}$ Principal, Simpson Gumpertz \& Heger, Inc., San Francisco, CA, USA Email: rohamburger@ sgh.com ${ }^{2}$ Executive Director, Applied Technology Council, Redwood City, CA USA Email: crojahn@atcouncil.org ${ }^{3}$ Director, Pacific Earthquake Engineering Research Center, Berkeley, CA, USA, Email: moehle@peer.berkeley.edu

${ }^{4}$ Principal, R.E. Bachman Consulting Engineer, Sacramento, CA, USA Email: rebachmanse@aol.com

${ }^{5}$ Principal, C. D. Comartin Inc., Stockton, CA, USA, Email: comartin@ comartin-reis.com

${ }^{6}$ Professor of Civil Engineering, State University of New York at Buffalo, Buffalo, NY, USA, Email: whittaker@ce.bufallo.edu
} 


\section{INTRODUCTION}

Design procedures for seismic resistance contained in building codes are intended to enable buildings to provide acceptable levels of performance in earthquakes, but the procedures are not truly performancebased. These procedures attempt to attain desired performance through specification of minimum acceptable levels of stiffness and strength, control of the detailing of structural elements and their connections, so as to provide adequate ductility, and control of the configuration of buildings, so as to promote favorable dynamic response characteristics and avoid the premature formation of mechanisms and other instabilities. While it is generally understood, and sometimes stated in commentary that the performance intent of these code procedures is to protect life safety, and, for some critical structures to minimize the potential for earthquake-induced damage and occupancy interruption, the level of protection provided is only qualitatively stated. The procedures themselves have been developed in an iterative process over a period of nearly one hundred years. In part the basis for this development has been scientific study of the characteristics of strong earthquake ground shaking, the response characteristics of structures affected by this ground shaking and the failure mechanisms that result in unacceptable performance, but to an even greater extent, the code procedures are based on simple observation of the unacceptable performance, in actual earthquakes, of structures having certain design and construction characteristics, and the development of rules to prohibit future construction of buildings with similar characteristics. Buildings designed using these procedures have diverse performance capability. Most will be able to fulfill the basic code intent of protecting life safety. Some will be capable of resisting intense ground shaking with limited damage or interruption of use while others will sustain extensive damage in even moderate levels of ground shaking. Designers relying on these code-based procedures have little guidance as to how their designs should be adjusted to either reduce the potential for damage in some buildings or avoid excessively costly construction practices in others while still attaining desired earthquake protection.

Performance-based design is an alternate approach that permits design of buildings with a realistic and reliable understanding of the probable performance in future earthquakes, expressed in quantitative statements of the risk of casualty, occupancy and economic losses termed performance objectives. In its purest form, it entails development of a preliminary design, mathematical modeling of the design, simulation of the design's response to various earthquake events and comparison of the predicted performance in these events with the performance objectives adopted as the design criteria. If the performance predicted in the simulations is found to meet the stated objectives the design is acceptable. If the simulated performance does not meet the stated objectives, the design must be revised and the simulation process repeated, in an iterative manner, until the design has been demonstrated to be capable of acceptable performance. This approach may be used to design individual facilities with a better understanding of their likely performance than is attainable using prescriptive procedures, design individual facilities that are more loss-resistant than typical buildings designed using prescriptive criteria, and design individual facilities that are capable of meeting the performance intent of the prescriptive criteria, but which do not comply with all of the limitations of the prescriptive criteria with regard to configuration, materials and systems, and potentially at lower cost. Another important application of performance-based design procedures is that they enable the performance capability of buildings designed to current prescriptive procedures to be quantified and to enable modification of these prescriptive procedures to better provide the desired performance.

In the United States, interest in performance-based seismic design initiated in the 1980s among engineers engaged in seismic retrofit of existing buildings. Owners of existing buildings would not commit to investment in retrofit construction unless they had an understanding of the probable performance of their buildings in future earthquakes, decided that this performance was undesirable, and that acceptable performance could be obtained at reasonable cost. Engineers quickly found that evaluations of buildings 
to the current editions of the building code provided information on the building's conformance to current design practice but did not provide direct information on the way a building was likely to behave in an earthquake. Thus, engineers began to develop rudimentary procedures for assessing the likely earthquake performance of existing buildings so that they could evaluate whether collapse or other life-threatening damage was likely, and if not to assess the severity and likely consequences of damage that would occur. Initially, engineers had to rely on their own personal judgment and experience to perform these assessments. In the mid-1980s, the Applied Technology Council published several documents that standardized practice in this area. The ATC-13 report (ATC, [1985]) provided statistical data on the probable repair costs for buildings of different types, based on the opinions of earthquake engineering experts, while the ATC-14 report (ATC, [1987]) provided a standardized methodology for evaluating life safety hazards in buildings. While these documents enabled engineers to evaluate buildings with a common approach, they provided no guidance on how to retrofit buildings to achieve improved performance. Therefore, the Federal Emergency Management Agency sponsored the development of rehabilitation design guidelines, which were initially published as the FEMA-273 report (ATC [1997]) and which were subsequently updated and republished in the form of a preliminary design standard, FEMA-356 by ASCE [2002]. Together with several contemporary publications (SEAOC [1996], ATC [1996]), these reports provided the first comprehensive methodologies for designing structures to provide desired seismic performance and as such, define the first generation of true performance-based seismic design procedures.

These first-generation procedures represent a significant improvement over past practice. They include standard methods of defining performance in terms of quantified performance levels that relate to calculated seismic response parameters, e.g. interstory drift and ductility demands, and incorporate a formal methodology for simulating building response to earthquake motions and assessing performance capability based on the predicted magnitude of a series of structural response parameters. From this perspective, they are truly performance-based. However, many improvements can be made to these procedures: For example:

- $\quad$ The current procedures evaluate performance on the basis of the demands and capacities of individual components, rather than global building behavior. The result of this is that the weakest and least ductile elements in a building tend to control the prediction of overall structural performance, even though they may have relatively little significance to the building's overall seismic resistance. For many structures, this may result in overly pessimistic assessment of a structure's performance capability and unnecessarily conservative design.

- $\quad$ Much of the acceptance criteria contained in the documents, and used by engineers to evaluate the acceptability of a structure's performance is based on the judgment of those who developed the method, rather than laboratory data or other direct substantiating evidence. Thus the reliability of the procedures is questionable.

- The procedures for evaluation of nonstructural elements is limited almost entirely to consideration of the ability of these elements to remain structurally stable, usually through attachment to the structure, and do not address well either the damageability or post-earthquake functionality of these components and systems comprised of these components. Since much of the losses experienced by buildings in past earthquakes can be attributed to the performance of these nonstructural components and systems, this represents a significant impediment. 
- The reliability of the procedures and their ability to actually achieve the desired performance has never been established. Though many engineers believe that the procedures are excessively conservative, in fact, for many structures, they may not result in adequate performance capability.

- $\quad$ The standard performance levels do not directly address some primary stakeholder concerns, that is probable repair costs and time of occupancy loss in the building, due to earthquake induced damage

- $\quad$ The basic process of performance-based engineering, in which the design professional promises to design a structure capable of meeting a specific set of performance objectives, carries with it significant potential liability as many building owners may perceive that the design professional has provided a warranty on the design's performance capability.

The purpose of the ATC-58 project is to develop a next generation performance-based seismic design criteria for buildings that will address these issues. Initial planning for the project was outlined in an action plan, FEMA-349 (EERI [1998]) developed by the Earthquake Engineering Research Institute based on broad community input. The project is being executed in two phases, each with an anticipated duration of 5 years. The first phase is currently underway and will include identification of preferred ways of communicating seismic performance of buildings with the building owners and other stakeholders who must decide what performance is appropriate for specific buildings. In addition the first phase will include development of a comprehensive building seismic performance assessment methodology. When complete, this performance assessment methodology will be suitable for direct application to performance-based design of new buildings or performance-based retrofit design for existing buildings. However, engineers using the methodology for that purpose will not have any guidance, other than their own judgment, on how to develop designs that are likely to be capable of providing the desired performance. Thus, the performance-based design process using this methodology could be quite inefficient unless the engineer using the procedure is capable of developing preliminary designs that have the necessary performance characteristics. The second phase of the project, which will be conducted upon conclusion of the first phase will focus on the development of design guidance to assist the engineer in efficiently identifying designs likely to be capable of providing the desired performance.

The ATC-58 project will not include the performance of any basic research. Instead, the project must rely on the research performed by the three national earthquake engineering research centers, research performed under the NEES and ANSS programs, and by other independent researchers. The project is closely coordinating with the three national earthquake research centers in order to facilitate the necessary knowledge transfer. In addition, the project is coordinating with parallel efforts underway in the blast and fire engineering communities to assure that design and evaluation methodologies developed for earthquake hazards are compatible with those developed for other hazards.

\section{PERFORMANCE CHARACTERIZATION}

An important goal of the ATC-58 project is to utilize performance objectives that are both predictable, by the design professional, and meaningful and useful for the decision makers who must select or approve the performance objectives that are used as a basis for design of individual buildings. Initial project tasks have included outreach to representative decision makers including building developers, lenders, insurers, corporate risk managers and building officials, among others, in order to determine how earthquake performance can best be communicated to such non-technical decision makers in a way that will facilitate 
their decision making processes. These tasks have revealed that these decision makers are a disparate group, having widely varying performance concerns, levels of sophistication and decision making styles. Decision makers include building developers, corporate facilities managers, corporate risk managers, institutional managers, lenders, insurers, public agencies, regulators and others. Each of these decision makers will view seismic performance from a different perspective and select desired performance using different decision making processes. Many decision makers will default in the selection process to the minimum performance permitted by regulatory authority. Others will select acceptable performance based on risk of ruin considerations and maximum foreseeable event scenarios. Still others may select desired performance based on elaborate cost-benefit or financial rate of return calculations. Regardless of the process, selection of appropriate performance objectives will involve development of an understanding of the risk associated with a given choice and the resources that must be invested to reduce this risk beyond certain thresholds. Thus, a central part of the performance-based design methodology must include procedures for quantifying seismic risk on a design-specific basis. Given the different needs of the various decision makers, it is important to be able to express these risks in a flexible manner, that suits the needs and styles of the individual decision maker. It is important to be able to express risk on either a deterministic event (scenario) basis, the preferred method for many less-sophisticated decision makers, or on a probabilistic basis, an approach more popular with some corporations, financial services firms and insurers. It is also important to be able to express risk in terms of specific losses, for example, cost of restoration of a facility to service once it is damaged, time to restore a facility to service once it is damaged and potential for life loss or life-threatening injury resulting from damage. These losses, or decision variables, rather than the damage itself, or arbitrary performance levels, are most meaningful to the broad range of decision makers. Thus, in the next-generation performance-based design methodology, performance will be characterized directly in terms of the expected losses and in a variety of formats including the following:

- $\quad$ Maximum expected earthquake-related repair cost in a 500-year period

- $\quad$ Expected days of business interruption given the occurrence of an M7 earthquake on a neighboring fault

- $\quad$ Average annual probability of life loss

Prediction of the likely performance of a building in future earthquakes is subject to many uncertainties. Neither the location or magnitude of future earthquakes is known, and even if these were well defined, we are not currently capable of precisely predicting the characteristics of ground motion that will occur at a specific building site. Similarly, our models of buildings used to simulate performance are unlikely to accurately represent the precise construction characteristics of the real building or be capable of simulating the actual damage that will occur in an earthquake. Therefore, any estimates of future performance, such as those expressed above, may either under state or over state the actual risk. It is important to be able to quantify the extent of uncertainty associated with performance assessments, both so that the decision maker understands the quality of the data upon which decisions are being made and so that engineers, at least in part, are not expected to have provided performance warrantees with designs executed using performance-based procedures. In the next-generation procedures, performance assessments, such as those stated above will be qualified with an indication of the confidence associated with the estimate or potentially, by indicating potential bounds on the likely risk. 


\section{PERFORMANCE ASSESSMENT METHODOLOGY}

In order to calculate building performance as indicated in the previous section, the ATC-58 project is adopting and developing a performance assessment methodology based on the framework equation developed at the Pacific Earthquake Engineering Research Center (Baker [2003]). In its simplest form, the framework equation appears as:

$$
E[D V]=\iiint \int p(D V \mid D M) p(D M \mid E D P) p(E D P \mid I M) p(I M)
$$

where, $I M$ is a parametric representation of ground motion intensity, such as peak ground acceleration and $p(I M)$ is the probability of experiencing a given level of intensity; $E D P$ is a parametric representation of structural response to ground motion, such as interstory drift, and $p(E D P \mid I M)$ is the conditional probability of experiencing a level of response, given a level of ground motion intensity; $D M$ is a parametric representation of a damage state such as spalling of concrete cover, fracture of steel connections, or structural collapse, and $p(D M \mid E D P)$ is the conditional probability of experiencing the damage state, given a level of structural response; $D V$ is a parametric expression of the loss, sometimes also termed a decision variable, expressed in terms of repair costs, casualties or lost occupancy time, and $p(D V \mid D M)$ is the conditional probability of experiencing a loss of certain size, given a level of damage. The expected loss or value of the decision variable $E[D V\}$ is calculated as the sum of these quantities over all levels of intensity, all levels of response, all levels of damage, and all levels of loss. The following sections discuss how this process will be implemented for a typical structure.

\section{Ground Motion Intensity}

The probability of experiencing ground motion of given intensity, $p(I M)$ is expressed in the form of a hazard function for a site. The hazard function may be formed on a scenario basis, that is considering only the occurrence of a specific magnitude earthquake on a specific fault, or on a probabilistic basis, considering all potential earthquakes on all known faults and seismic source zones.

Scenario-based hazard functions indicate the conditional probability of exceedance of different intensities of motion given that the scenario earthquake occurs. Figure 1 presents a scenario-based hazard function for a hypothetical site and scenario earthquake event, showing the median conditional probability of exceeding different intensities of ground shaking, expressed as peak ground acceleration (pga), given that the scenario earthquake occurs. In addition to the median conditional probability, the figure also illustrates that confidence bands may be associated with these probabilities, owing to uncertainties associated with estimation of the hazard. This figure illustrates, for example, that with median confidence, there is only a $10 \%$ chance that ground shaking from this scenario earthquake would exceed a pga at the site of $0.4 \mathrm{~g}$. It also illustrates a $10 \%$ level of confidence that there is less than a $10 \%$ chance of experiencing ground shaking with a pga of $0.2 \mathrm{~g}$ and a $90 \%$ level of confidence that there is less than a $10 \%$ chance of experiencing ground shaking with a pga of $0.5 \mathrm{~g}$, given that this particular earthquake scenario occurs. Probabilistic hazard functions will indicate the total probability of exceeding different intensities of motion, considering all earthquakes that may occur and the probability and associated confidence of each of these events. The probability may be expressed in the form of an annual probability of exceedance (or nonexceedance), an average return period, or the probability of exceedance (or nonexceedance) in a defined period of years, often taken as 50. It can be expressed as a mean probability, in which the uncertainty associated with the function is averaged, or confidence bounds can be expressly indicated, as in Figure 1. Because there is a physical limit, both on the magnitude of earthquakes that can occur on a various faults and also on the intensity of motion that can occur, given that a certain magnitude event occurs, the hazard functions tend to be asymptotic to a limiting value. 


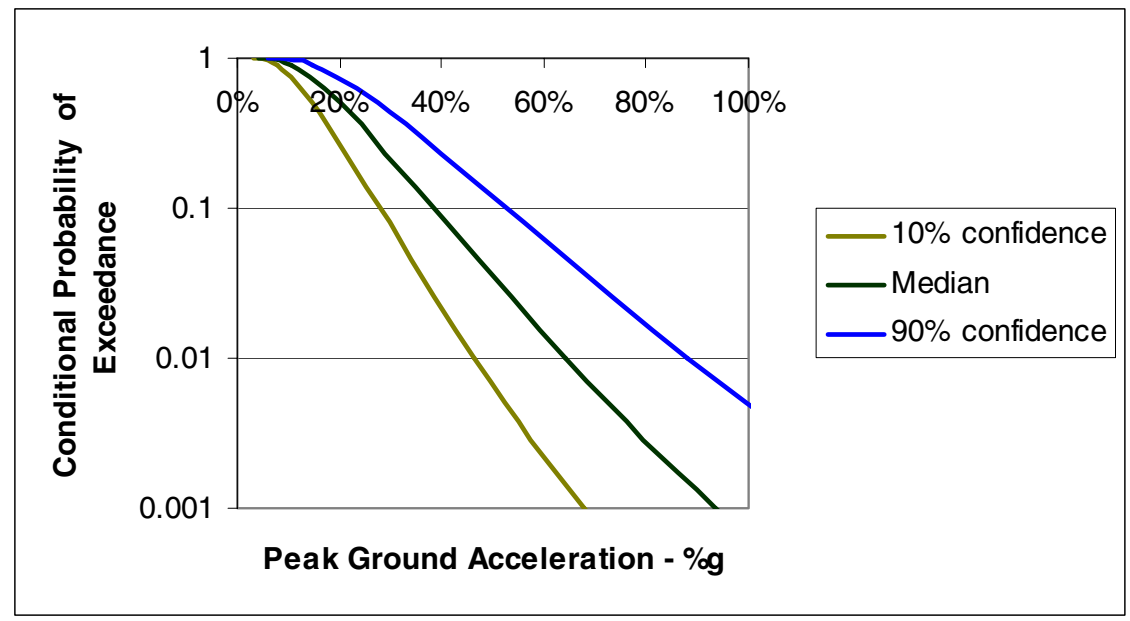

Figure 1 - Hypothetical Scenario-based Hazard Function for Site

In the figure, peak ground acceleration has been used as the parameter by which ground motion intensity is expressed. It is desirable that intensity measures be both useful and efficient. For a measure to be useful it must be compatible with the structural analysis that will be used to evaluate structural and nonstructural response and must correlate well both with response and damage. In addition, it must be a parameter that can be predicted as a function of earthquake source, travel path and site characteristics either using empirical or analytical approaches so that a hazard function (or preferably, national hazard maps) can be developed for the measure. An intensity measure is efficient if the variability associated with predictions of response and damage that are associated with it tend to be small.

Intensity measures which have been suggested for use in predicting structural response and damage include elastic spectral response acceleration at the first mode structural period, inelastic spectral displacement demand at the first mode structural period, and vector methods that include consideration of both first and higher modes of structural response.

\section{Structural Analysis}

Structural analysis is used in the performance assessment process for two basic purposes. First it is used to predict the values of the structural response quantities (engineering demand parameters) that are used as predictors of damage, and second it is used to predict the values of floor response acceleration and interstory drift that serve as intensity measures for the evaluation of nonstructural response and performance.

Focusing on the first of these two purposes, for a given structure and a given level of ground motion intensity, structural analysis is used to predict the value of one or more engineering demand parameters that in a later step of the process, can be used to predict structural damage. As an example, as an intensity measure, we select 5\% damped elastic spectral response at the structure's fundamental period, $S_{\mathrm{a} 1}$ and as an engineering demand parameter that is predictive of damage we select interstory drift. We can choose a ground motion record that is representative of the source, path and site characteristics appropriate to the site hazard at a given level of intensity and scale this record so that it is compatible with the spectrum. Next we can perform a nonlinear dynamic analysis of the structure, using this record and predict the peak interstory drift demand $\operatorname{IDD}\left(S_{a l}\right)$. The value of the interstory drift demand predicted by this analysis will depend on several factors including our assumptions as to the structure's mass, stiffness, strength, damping, and hysteretic characteristics as well as the specifics of the ground motion record itself. If we 
had selected a different ground motion record for the analysis, but left all of the modeling parameters unchanged, we would have predicted a somewhat different value for the interstory drift, and, if we were to repeat this process using several different records, each, would in general, result in somewhat different predictions of the interstory drift demand. If we believe each of these records is equally representative of the spectrum and the hazard, the result is a random distribution of interstory drift demand that can result from this particular ground motion intensity level. This distribution can be characterized by a mean or median value and a measure of the random variation. If this process is repeated for a range of ground motion intensities, as represented by spectra scaled to different values of the spectral response acceleration, it is possible to develop a structural response function that indicates the probable distribution of the engineering demand parameter (interstory drift) for different levels of ground motion intensity (spectral response acceleration). Figure 2 is illustrative of such a structural response function for a hypothetical structure, showing the median prediction of interstory drift demand as a function of ground motion intensity as well as interstory drift demands at $10 \%$ and $90 \%$ probabilities of exceedance.

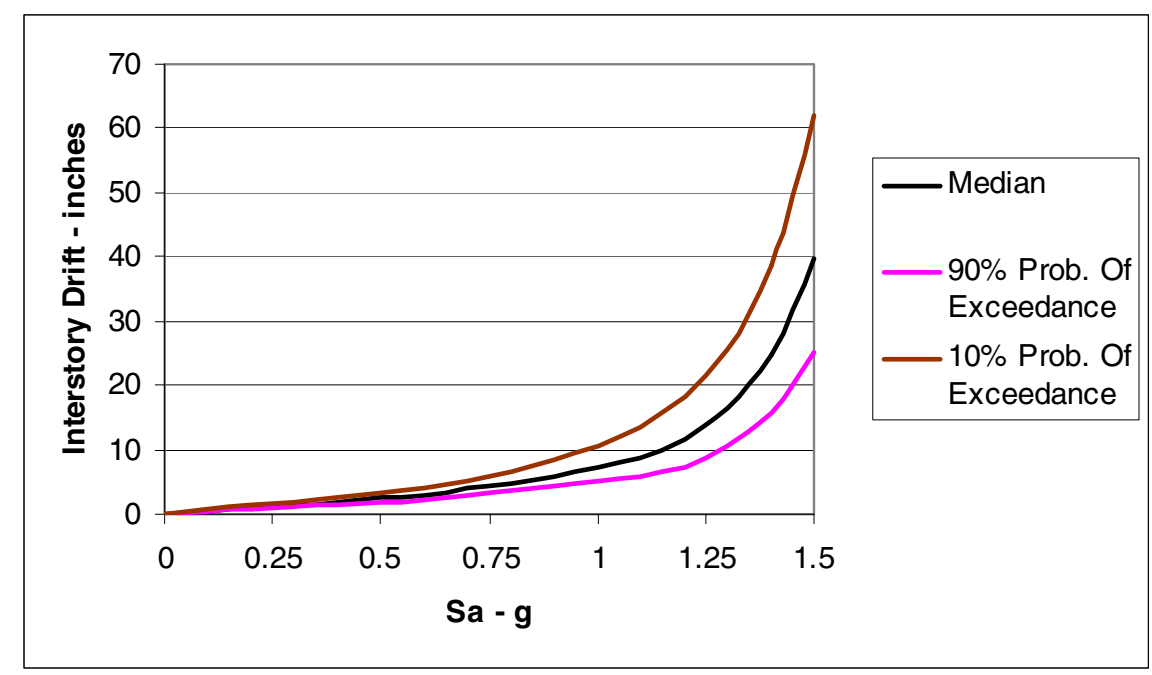

Figure 2 - Hypothetical structural response function for building

In the development of the structural response function illustrated in figure 2, the stiffness, mass, damping and hysteretic parameters for the structure were held invariant, as if the true value of these parameters was precisely known. While most likely values for these parameters can be estimated, in fact, the true values are seldom, if ever known, and there is some uncertainty as to what their precise values are. To the extent that the values for these parameters used in the analyses are inaccurate, the resulting structural response function for the building may either over- or under- predict the response at a given level of ground motion intensity. While it is essentially impossible to predict the exact value of any of these parameters, it is possible to estimate most likely values for each of these as well as upper and lower limits. If a series of analyses of the structure are performed, varying these parameters within these limits, it is possible to predict the additional variation in possible interstory drift demand at a given level of ground motion intensity resulting from these uncertainties. These additional uncertainties will tend to broaden, somewhat, the scatter associated with the response function, as illustrated in Figure 3. For a real structure, the task of defining these uncertainty bounds considering the various random variables involved is a complex process requiring many analyses. As an alternative to this complex process, it is possible to estimate the confidence bounds by assuming that the variability can be represented by a standard shape of distribution, typically lognormal, and by selecting a coefficient of variation based on either expert judgment or the variability observed in analysis of a limited number of standard structures. 


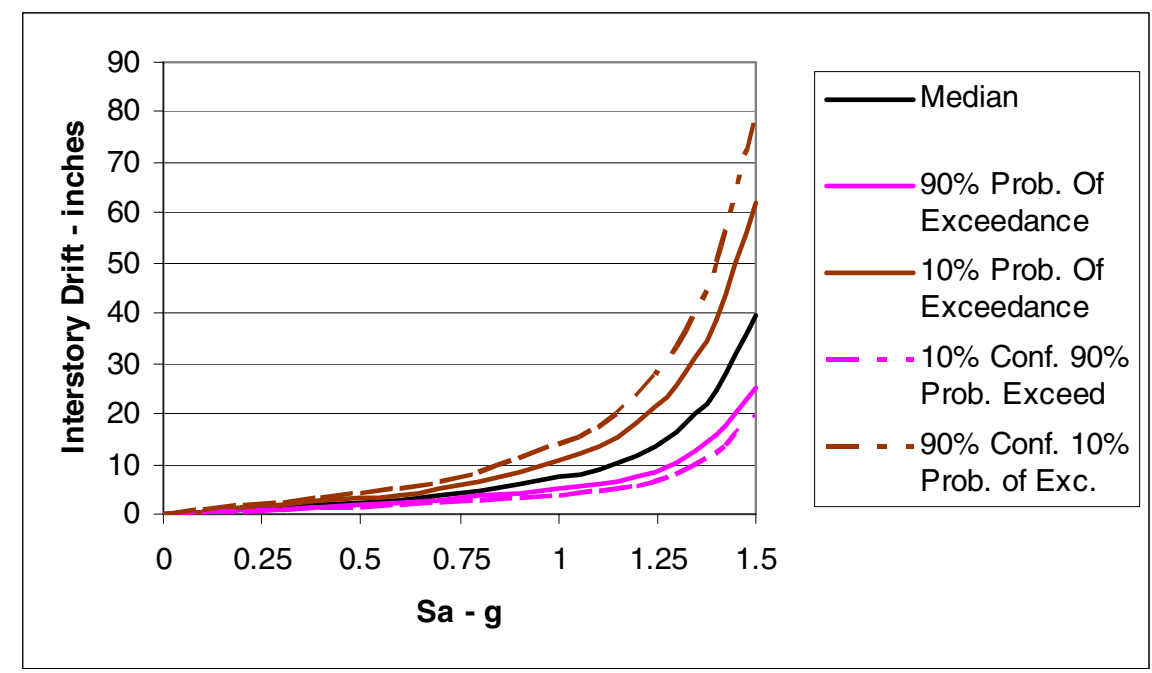

Figure 3 - Hypothetical Response Function Indicating Uncertainties

Real structures are composed of many elements and can experience different types of damage to these various elements as well as global damage such as permanent interstory drift and collapse. A number of different engineering demand parameters may be required to predict the onset of different types of damage to the various components that comprise the structure and to the structure itself. In addition to interstory drift, used in the above example, other engineering demand parameters that may be useful include inelastic deformation of the various components, strength demand on various components and similar response quantities.

\section{Structural Fragility}

Structural fragilities are functions that relate the probability that a structure will experience damage greater (or less) than a certain level, given that it is driven to a certain level of response, as measured by the engineering demand parameter(s). As is the case with response functions, fragilities are expressed as probability distributions, rather than deterministic relationships in order to account for the variability and uncertainty inherent in the process of predicting structural damage as a function of structural response. The variability is associated with such factors as the random character of structural response to individual ground motion records and the inability of simple engineering demand parameters to distinguish between this response variation and the damage it causes. For example, two different ground motions may each produce peak interstory drift demands of 4 inches in a structure, however, one of these ground motions may cycle the structure to this drift level one time then restore the structure to small oscillations about its original position while the second ground motion may cycle the structure to this drift level several times and leave the structure displaced nearly to this level. Clearly the latter motion will be more damaging of the structure than the first motion, though the value of the engineering demand parameter is the same. Such effects are not predictable unless the precise ground motion and structural response is known. Uncertainty is introduced through such factors as lack of precise definition of material strength and construction quality.

In order to form fragility functions it is first necessary to establish measures of damage. A variety of such measures are possible. Early research in this area used the concept of damage indices as measures of damage. Damage indices are non-dimensional parameters, typically having values in the range of 0 to 1 where a value of 0 would indicate no damage and a value of 1 would indicate total damage. Most such damage indices have been developed on an element or component basis while a few have been calculated 
on a global structural level. Generally, these damage indices are specific to a particular type of structural component or structural system. Most are of the general form:

$$
D I=\left(\frac{\Delta_{i}}{\Delta_{u}}\right)^{x}+\left(\frac{E_{i}}{E_{u}}\right)^{y} \leq 1.0
$$

where the quantity $\left(\Delta_{\mathrm{i}} / \Delta_{\mathrm{u}}\right)$ is the ratio of the maximum inelastic displacement or deformation demand induced in the structure (or component) to the ultimate displacement capacity of the structure and the quantity $\left(\mathrm{E}_{\mathrm{i}} / \mathrm{E}_{\mathrm{u}}\right)$ is a measure of cumulative damage resulting from repeated cycles of inelastic response and has most commonly been expressed in the past as a ratio of inelastic energy dissipation.

It is difficult to relate such damage indices to repair costs and other measures of loss. Therefore, the ATC58 project will more likely parameterize damage through direct tracking of the condition of individual structural elements and components, on a piece by piece basis, coupled with measures of global damage. For example, for moment-resisting steel frames, damage measures that could be used could include, on a joint-by-joint basis, panel zone yielding, beam plastic hinging, beam flange buckling, and welded joint fracturing, while measures of global damage could include tracking of residual interstory drifts of different amounts (e.g., 1\%, 2\%, 3\%, etc. up to collapse) on a story by story basis. Each of these damage states would have different implications with regard to post-earthquake safety, repair effort and cost, and occupancy interruption. The consequences of each of these individual damage measures would have to be aggregated on a system basis, over the entire structure.

Fragilities may be formed on either a "structure-specific" or structural system-specific basis. Absent a practical ability to build prototype structures, test them, and measure the amounts of damage that have occurred, fragilities must be formed on the basis of analysis, laboratory data on component performance and expert judgment. As an example, fragilities are constructed here for the case of moment-resisting steel frames, based on data obtained from the FEMA/SAC (SAC Joint Venture [2000]) program. For this example, fragilities are limited to the case of regular, low-rise Special Moment Resisting Frames employing reduced beam section connections. Component damage measures for this structural class are taken as "initiation of beam yielding," "beam flange buckling," "beam flange fracture," and "permanent interstory drifts of $1 \%, 2 \%, 3 \%$ and story collapse. Following recommendations from the FEMA/SAC project, a single engineering demand parameter, peak interstory drift ratio, will be used for each of these damage measures. Based on the FEMA/SAC study, the median value of interstory drift at which beam flange yielding initiates is 0.01 radians, at which beam flange buckling initiates is 0.02 radians, and at which beam flange fracture initiates is 0.06 radians. A best "estimate" of permanent interstory drift is $50 \%$ of peak interstory drift and a best estimate of the interstory drift at which collapse initiates is 0.1 radians. Coefficients of variation associated with each of these behaviors are estimated at 0.1 for initiation of yielding, .2 for initiation of buckling, 0.3 for initiation of flange fractures and permanent interstory drift and 0.5 for initiation of collapse.

Figure 4 indicates the fragilities for individual beam-column connections developed using this data and assuming lognormal distribution while Figure 5 indicates global measures of fragility computed in a similar manner. For the purposes of this example, a story height of 12 feet has been assumed, so that interstory drift ratios may be expressed in the same form (interstory drift) as the response function shown in Figure 3. 


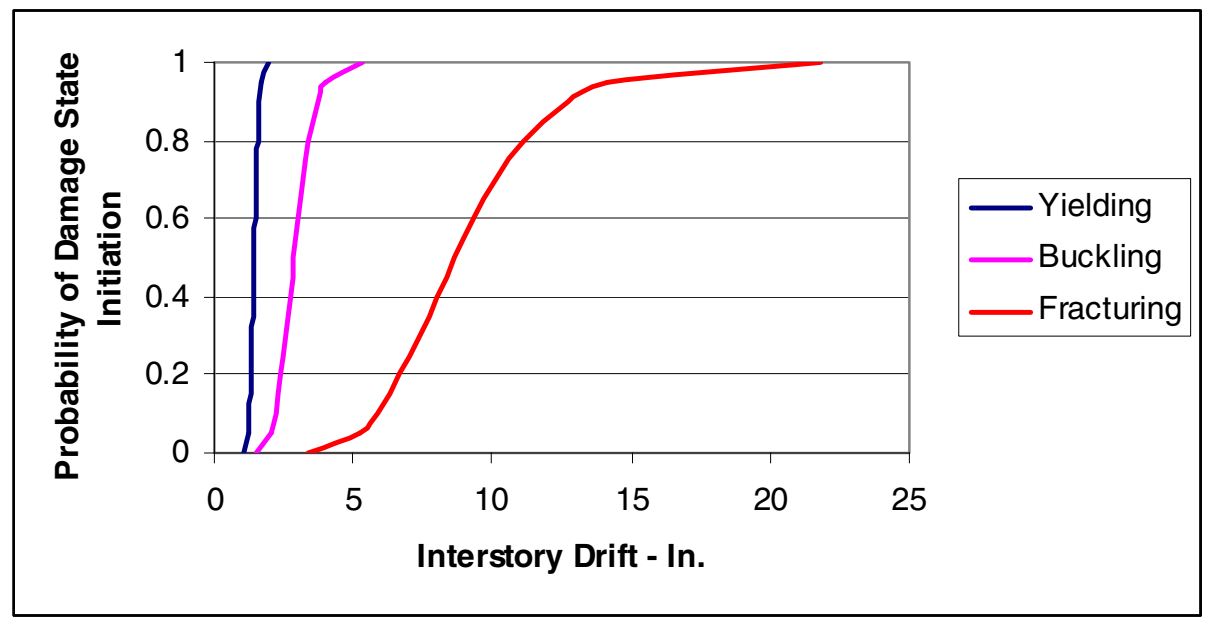

Figure 4 - Example Fragility Function for Beam-Column Connection Behavior

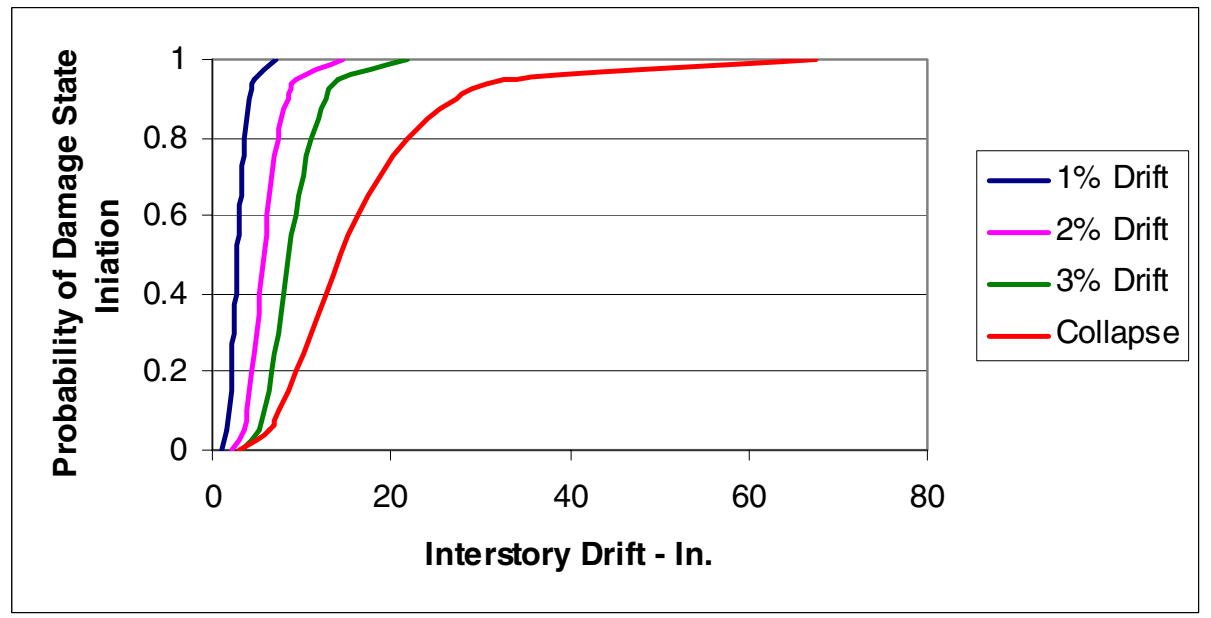

Figure 5 - Example Fragility Function for Global Structural Behaviors

The fragility curves do not directly indicate the probability that damage will be in any of these states, but rather, the probability that damage will be equal to or greater than that corresponding to a specific state. To determine the probability that a structure will be in a given damage state at a given level of response it is necessary to take the difference between the probabilities that it initiates damage within the given state and the probability that the structure will initiate damage in the next most severe state. For the fragility curve indicated in Figure 4, for example, at an interstory drift demand of 5 inches there is virtually a 100\% chance that beam flanges will have yielded, approximately a $95 \%$ chance that buckling damage will have initiate in flanges and approximately a $5 \%$ chance that fracturing of the beam flanges or welded connections will have occurred. Thus, at an interstory drift of 5 inches, there is a $5 \%$ chance that beam flanges will be yielded but not buckled, a $90 \%$ chance that beam flanges will be buckled, but not fractured and a 5\% chance that they will be fractured. Similarly, at a peak interstory drift demand of 5 inches, there is a $96 \%$ probability that the structure will sustain permanent interstory drift of $1 \%$ or greater, a $32 \%$ probability that the structure will sustain permanent interstory drift of $2 \%$ or greater, a $3 \%$ probability that the structure will sustain permanent interstory drift of $4 \%$ or greater. Thus, the probability that the structure's permanent interstory drift will be between $0 \%$ and $1 \%$ is $4 \%$ (the difference between $96 \%$ and $100 \%$ ), the probability that the structures' permanent interstory drift will be between $1 \%$ and $2 \%$ is $64 \%$, and between $2 \%$ and $3 \%$ is $29 \%$. At this interstory drift level, there is negligible probability of collapse. 


\section{Nonstructural Fragility}

Nonstructural fragilities serve the same purpose as structural fragilities, except that they indicate the probability that nonstructural components, rather than the building structure, will be at or in excess of a given damage level as a function of an input intensity measure. The intensity measure used to predict nonstructural component or system damage will, in general, be different than that used to predict structural damage. Intensity measures that are likely to be useful for predicting damage of nonstructural components include peak floor response accelerations at the fundamental mode of the nonstructural component and peak inter-story drift at the levels of attachment of the component. Damage states that may be meaningful for nonstructural components and systems could include loss of function, loss of structural integrity and toppling. In general, each class of nonstructural component or system, such as suspended ceilings, fire sprinkler systems, interior partitions, etc, will have different fragility functions, tied to several different intensity measures. These can be determined through collection of earthquake performance data on damage sustained by actual installations, through laboratory testing programs and in some cases, through structural analysis, just as would be done for the building structure itself. Figure 6 is a hypothetical fragility curve for a single drift-sensitive nonstructural component (exterior curtain walls). The intensity measure for this fragility curve is taken as structural interstory drift. The damage states of interest are taken as cracking of panels, breakage of glass, fallout of glass, and failure of panel connections. The fragilities shown in the figure are illustrative only and are not representative of real data.

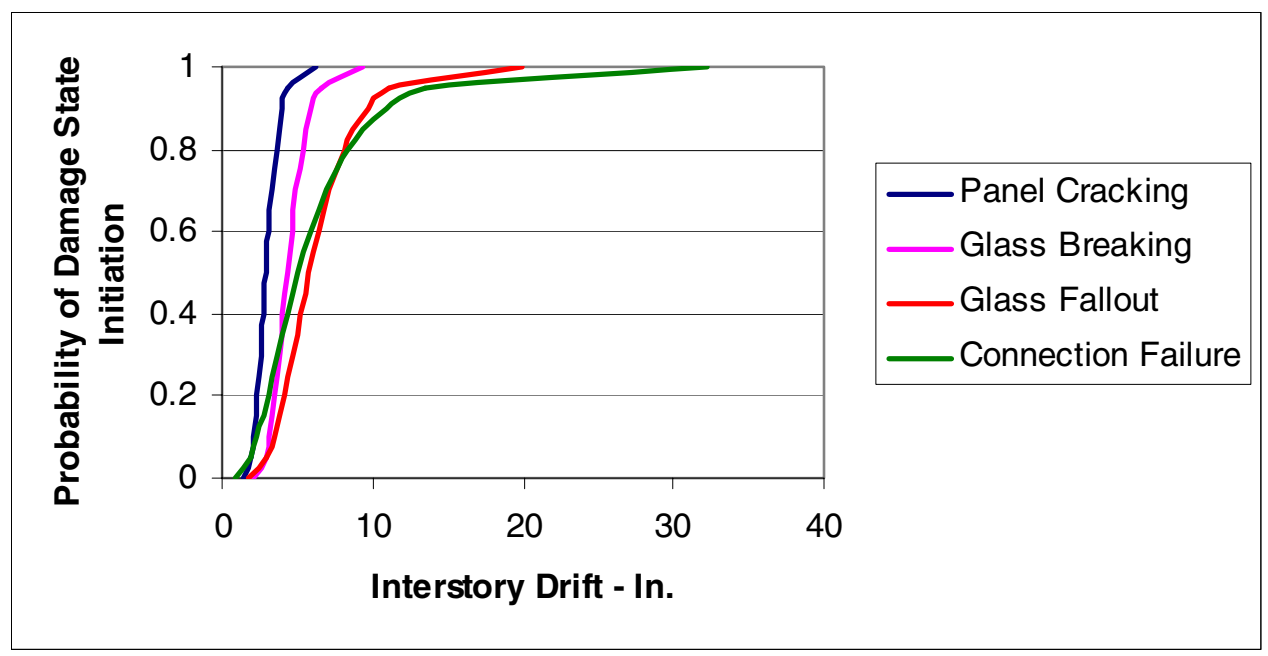

Figure 6 - Hypothetical Fragility Curve for Nonstructural Component

\section{Loss Functions}

Loss functions indicate the probability of incurring various levels of loss, given that a structure or nonstructural component or system is damaged to a given level, expressed in such parameters as repair cost, casualties (deaths and injuries) and hours of lost service or occupancy. These curves show the probability, that loss will be less than or equal to an indicated amount, given that the building is damaged to a given level. Loss functions can be constructed for a given building or class of buildings, by postulating damage to the structure (or nonstructural component/system) that is representative of a damage level for which there is an available fragility function, and estimating the losses associated with this damage. By varying the assumptions, or exploring the level of uncertainty associated with these assumptions inherent in these estimates, it is possible to determine probability distributions of the possible losses, as a function of the damage state. Alternatively, if sufficient historical data on actual losses incurred in past earthquakes are available, it should be possible to construct such curves directly from the historical data. 
Loss functions tend to incorporate significant uncertainty as compared with hazard curves, response functions and fragility curves because they are highly dependent on human factors including the owner's ability to act rapidly in retaining the necessary design professionals and construction contractors to effect repairs, the efficiency with which the design professionals and contractors operate and the speed with which building departments approve proposed repair programs.

Figure 7 is a hypothetical loss curve that relates repair cost for a single beam-column connection for a moment resisting steel frame structure for the several damage levels indicated in Figure 7, i.e., beam flange yielding, beam flange buckling and beam flange fracturing. It is roughly based on the estimated cost of repairing moment-resisting steel frames developed during the FEMA/SAC program. Figure 8 is a hypothetical loss curve for fatalities given that story collapse occurs. The curve in Figure 8 was developed for illustrative purposes by assuming that if collapse occurs in a story there is essentially a certainty that all lives in the story are lost, that the median occupancy of a building of this type is one person per 2,000 square feet, and that the coefficient of variation associated with this is 1 .

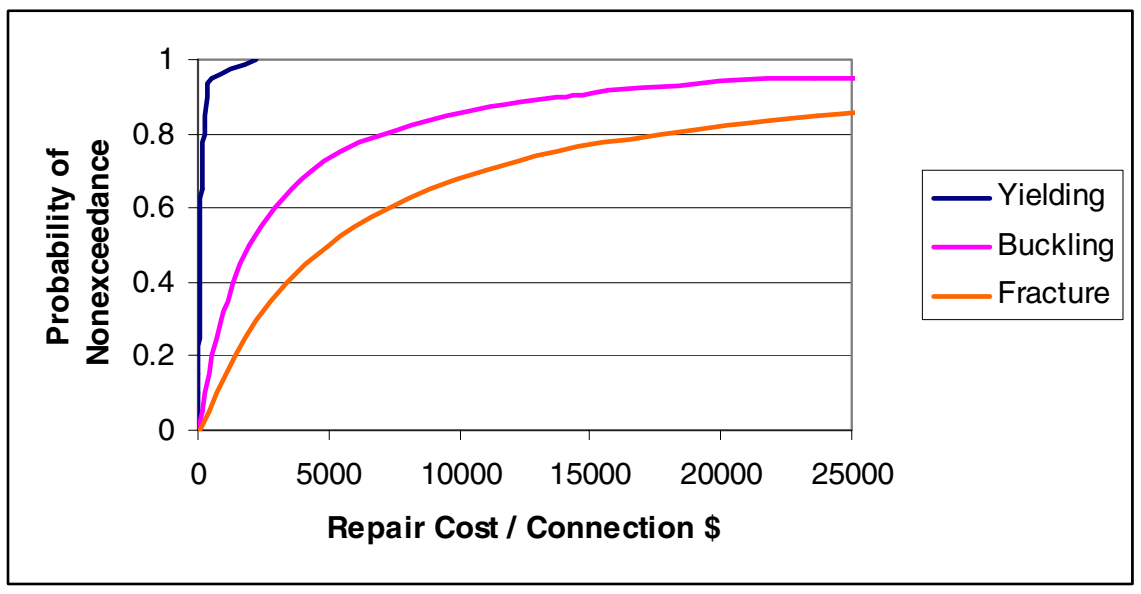

Figure 7 - Hypothetical Loss Curve for Moment-Resisting Steel Frame in \$/ Damaged Connection

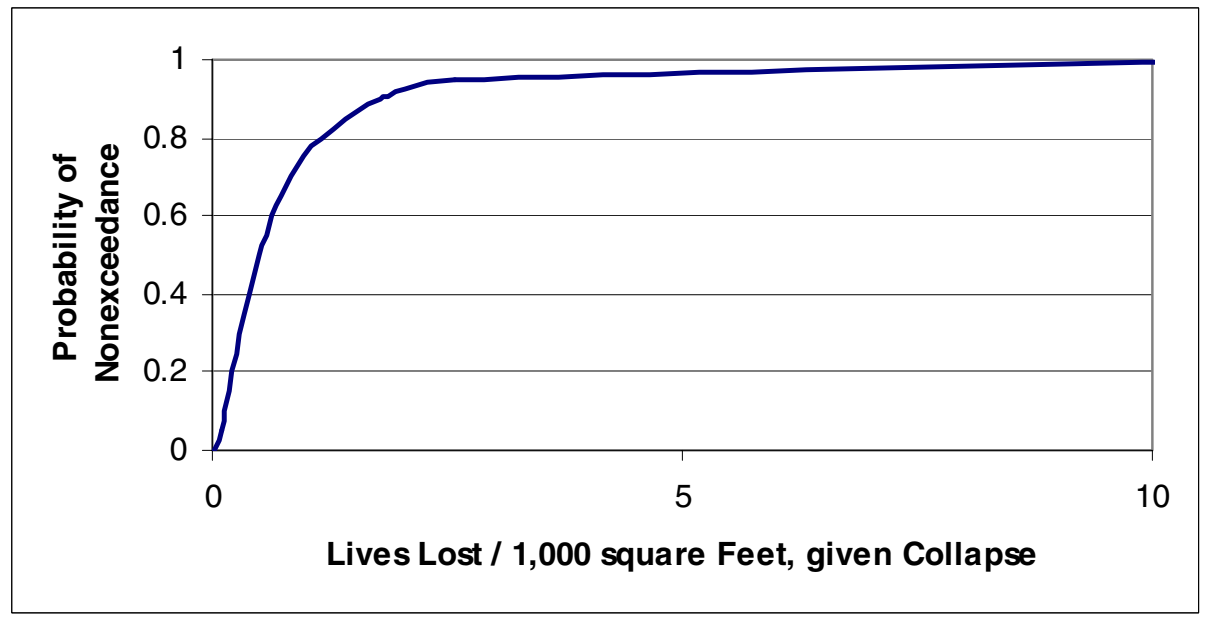

Figure 8 - Example Loss Curve for Building, Given Collapse of a Story 
Loss curves for various nonstructural components and systems could be developed in a manner similar to those indicated in Figures 7 and 8, but are not shown here for brevity.

\section{Aggregation of Loss}

Once hazard, response, damage and loss functions of the types illustrated in the previous sections are developed for a structure, in order to assess a building's performance capability it becomes necessary to perform the integration indicated in equation (1). This integration can be performed numerically, on spreadsheet or other software applications. Alternatively, if convenient functional forms are fitted to the various functions, closed form solutions for the integral can be derived.

\section{DESIGN GUIDELINES}

The first 5-year phase of the ATC-58 project will focus on the development, in user-friendly form, of the performance-assessment methodology discussed in the previous sections. It is anticipated that even for simple structures, this methodology will be somewhat complex and time consuming to implement and would not be suitable for routine application on many design projects. Further, even for those projects where its implementation would be justified, the engineer would not want to go through the performance assessment procedure many times, in order to find a design that is capable of meeting desired performance objectives. Therefore, the second 5-year phase of the project will concentrate on the development of design guidelines that will enable engineers to efficiently and rapidly identify design strategies and preliminary designs that will be capable of achieving various performance objectives.

It is anticipated that much of the second phase of the project will consist of implementing the performance assessment methodology to evaluate the performance of hypothetical model buildings and by varying design parameters, including stiffness, strength, ductility, damping, and configuration, determining

relations between these design parameters, that engineers are used to considering, and performance. Since building performance is often dominated by the performance of nonstructural building components and systems, which tend to be quite occupancy-specific, it will be necessary to perform this exercise for buildings of a number of different occupancy types including commercial office, residential, manufacturing, health care and education.

It is hoped that upon completion of this second phase, engineers will have direct rules that can be used to design typical structures with specific performance expectations and that they will need to implement the full performance assessment methodology, only when desiring structures with special performance characteristics, having unique configurations or structural systems.

\section{REFERENCES}

1. Applied Technology Council, Earthquake Damage Evaluation Data for California. Report No. ATC-13. Redwood City, CA. 1985.

2. Applied Technology Council, Evaluating the Seismic Resistance of Existing Buildings. Report No. ATC-14. Redwood City, CA. 1987.

3. Applied Technology Council, Seismic Evaluation and Retrofit of Concrete Buildings, Report No. ATC-40, Applied Technology Council, Redwood City, CA, 1996

4. Applied Technology Council, NEHRP Guidelines for Seismic Rehabilitation of Buildings, Report No. FEMA-273, Federal Emergency Management Agency, 1997 
5. American Society of Civil Engineers, Prestandard and Commentary for Seismic Rehabilitation of Buildings, Report No FEMA-356, Federal Emergency Management Agency, 2002

6. Baker, Jack and Cornell, C. Allin "Uncertainty Specification and Propagation for Loss Estimation Using FOSM Methods," Proceedings, The Ninth International Conference on Applications of Statistics and Probability in Civil Engineering (ICASP9), San Francisco, California, July 2003.

7. Earthquake Engineering Research Center, Action Plan for Performance-Based Seismic Design, Report No. FEMA-349, Federal Emergency Management Agency, 1998

8. SAC Joint Venture. State of Art Reports, Report No. FEMA-355 A, B, C, D, E and F, Federal Emergency Management Agency, 2000

9. Structural Engineers Association of California, Vision 2000 A Framework for Performance-Based Earthquake Engineering, Sacramento, California, 1996 